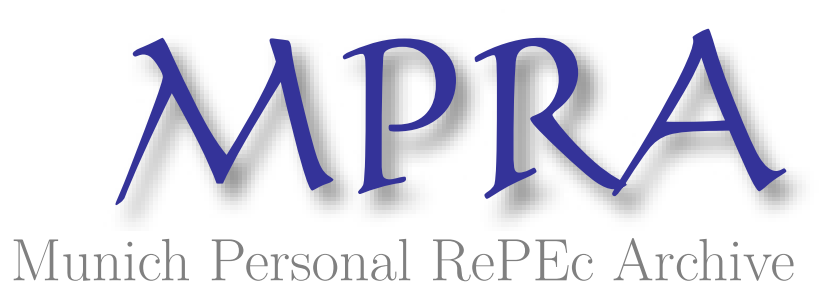

\title{
Does sports performance influence revenues and economic results in Spanish football?
}

Barajas, Angel and Fernández-Jardón, Carlos and Crolley, Liz

Universidad de Vigo

July 2005

Online at https://mpra.ub.uni-muenchen.de/3234/

MPRA Paper No. 3234, posted 15 May 2007 UTC 
Does sports Performance Influence ReVenues AND

ECONOMIC RESUlts IN SPANISH FoOtBall?

Angel Barajas, Carlos Fernández-Jardón and Liz Crolley

CONTACT DETAILS:

ANGEL BARAJAS:

University of Vigo

Dpto. Economía Financiera y Contabilidad Campus Universitario

32004 Ourense

Spain

Tel: 0034988368713

Fax: 0034988368923

email: abarajas@uvigo.es

CARLOS FERNÁNDEZ-JARDÓN:

University of Vigo

Dpto. Economía Aplicada

Campus Universitario Lagoas-Marcosende

36310 Vigo (Pontevedra)

Spain

Tel: 0034986812491

Fax: 0034986812401

email: cjardon@uvigo.es

Liz Crolley:

University of Liverpool

Management School

Chatham Street

Liverpool

L69 7ZH

UK

Tel: 00441517953809

Fax: 00441517953007

email: Icrolley@liverpool.ac.uk 


\title{
DOES SPORTS PERFORMANCE INFLUENCE REVENUES AND ECONOMIC RESULTS IN SPANISH FOOTBALL?
}

\begin{abstract}
English football began taking steps towards becoming a business earlier than Spanish football did, and academic studies on the football industry to date also focus primarily on football in the UK. The evidence for the relationship between sports performance and revenues appear clear in English football. There is even research about the effects of a club's wealth on its sports performance, or the effects of a club's sporting situations on its finances. In this paper, we analyse the relationship between sports performance and the revenues of football clubs as well as the effect of sports performance on the financial results in Spanish professional football. In order to carry out this research we have had to select which variables to analyse and choose the most appropriate methods of measurement. We have designed a system which obtains a variable of sports performance that includes information from every competition in which the football club participates.
\end{abstract}

Key Words: sports performance, economic results, football (soccer), football club finances. 


\section{INTRODUCTION}

Most studies about professional sport in the United States consider that clubs are profit maximisers. Sloan (1971) broke with this tradition pointing out that, at least for English football, profit-making clubs were not the norm. However, the incorporation for English football clubs to the financial markets might have changed this tendency for some clubs. In this context we were interested in the relationship between performance on the pitch and revenues in Spanish football, and whether or not the economic results of a club can be explained by its sports performance. Before outlining the results of the research, it is worth reviewing some of the most relevant studies on this topic.

The profit and loss account reflects the capacity that a company has to obtain (or not) a surplus from its turnover once all its expenses are deducted. For this reason, as far as economic results are concerned, it is worth observing the effect of sports performance on revenues, and the relationship of these revenues with costs Although both turnover and expenses really depend on managerial skills, the expenses are more easily controlled than turnover because income relates to consumer demand. Control of expenses would lead to profits. If there is no policy for expenses to achieve a margin, there is little chance of profitability.

Most research into economic and financial features of football analyse the relationship between sports performance and income, expecting them to be positive. Szymanski and Kuypers (1999) state that the proportion of the change in income during the $1996 / 97$ season is explained by $82 \%\left(R^{2}=0.82\right)$ by the English league position in that season. The result raises to an $R^{2}$ of 0.89 when they work with a longer period (1978-97). They use the logarithm of the revenues of each club divided by the yearly mean of the revenues of the all clubs as a whole. They conclude that winning teams, in the long term, are likely to attract high incomes.

Deloitte and Touche (1999; 2000 b) carry out analogous studies adjusting, by means of a non-linear regression, the total incomes of Spanish football clubs in the First Division with their ranking at the end of the league championships in seasons 1996/97, 97/98 and 98/99.

Clubs, in general, need funds to cover their expenses. These funds may come from operations but if the turnover is not high enough then most of the clubs will have to go into debt. In this sense, it can be stated that the greater the club's wealth, the higher its ability to spend money is and, as a consequence, the probability of it performing better on the pitch is also higher.

In this way, Murphy (1999 a and b) looks for the relationships between sporting performance and the rising wealth in English and Scottish football. He starts from the widespread idea that concentration of economic resources is inevitably reflected on the pitch and therefore in the performance rankings. He tries to test this hypothesis and whether or not a gap has appeared between the richest and 
the poorest clubs in the English and Scottish leagues. In the English case, his data do not deny a growing correlation between financial resources and sporting performance - measured by final league positions However, there are no clear indications that the accumulation of financial resources has broadened the gap between clubs. According to Murphy, there is a strong likelihood that some clubs from the Premier League will maintain their status whereas the position of others will weaken. As a consequence, these weaker clubs will be more likely to be relegated. Therefore the number of 'yo-yo' clubs ${ }^{1}$ increases. In the Scottish case, he observes that the gap - measured by points and goals - between the richest and the worst-off in the Scottish Premier League is narrowing. At the same time, the probability of one of the main clubs - Glasgow Celtic or Glasgow Rangers - winning the league is increasing. To summarise, he concludes that in the Scottish Premier League the relationship between economic results and sports performance is less direct and more complex than we might expect.

The Deloitte and Touche Annual Report (2000 a) also analyses the effects of relegation. Initially, it refers to the levels of attendance and states, although without a solid base, that in the season which follows relegation fans continue to attend matches through force of habit. However, it claims that other revenues, such as commercial or sponsorship, will be affected more dramatically.

The point of view offered by Noll (2002) in his study is slightly different, mainly because he approaches the issue from another perspective. Making use of English football data, he reaches the conclusion that players' wages of teams involved in promotion or relegation are higher than expected. At the same time, promotion and relegation have a positive effect on attendance and, finally, he thus maintains that the effects of promotion and relegation are ambiguous.

Developing this, Gerrard (2002) explores further the impact that relegation triggers on a club's finances. He returns to the initial proposition in that sports performance influences turnover and not the contrary, as Murphy maintained. After analysing the clubs relegated from the (English) Premier League in1999 and 2000 , he concludes that relegation has a double effect from a financial point of view. On one hand, relegated clubs have the advantage of enjoying greater incomes than the rest of clubs in their division. ${ }^{2}$ On the other hand, they have to face up to inflexible wage costs and run the increased financial risk if the clubs continue with high expenses in wages in order to try and win a quick promotion back to the Premiership. He also perceives a rise in relegation costs for 'yo-yo' teams and notes that hardly any club in this situation reduces its salaries.

Noll's first two conclusions concur with the aforementioned analysis of Gerrard (2002). He claims that one of the advantages of the European system of open leagues lies in the relevance that matches assume as a consequence of the fear of relegation and, at the same time, there are extra incentives for maximis-

\footnotetext{
${ }^{1}$ The term 'yo-yo' club is used to describe clubs that go 'down' and 'up' divisions, that is, they are relegated and promoted, sometimes repeatedly.

${ }^{2}$ They take advantage of the 'parachute' payments, aimed to soften the financial blow of relegation, which means that they share part of the revenues paid to the Premier League for their television rights.
} 
ing effort. Nevertheless, this system is also harmful. He mentions the rise in the cost of capital derived from the growing financial risk that clubs assume in their aim to win or avoid relegation. Finally, he points out that relegated clubs face the danger of being involved in a vicious circle.

As we have explained, there is no evidence of whether performance on the pitch is the cause of revenue levels or if these revenues, along with structural funds, are themselves the origin of better performances. In any case, we can argue the existence of a relationship that might constitute a virtuous circle: good performance implies higher turnover and funds that may be invested on improving the sporting results.

In accordance with the ideas just presented we aim to test whether or not in Spanish football, as in the English case, better performance on the pitch means higher revenues and whether good sports performance explains well the economic results of clubs.

So the structure of this paper begins by showing the features of the sample we have analysed (Section 2). Then in Section 3 we introduce the different measurements of sports performance used by academics in previous studies. We design an appropriate variable that includes the effect of performance in all competitions. It also involves assigning a ranking indicator for performance in knock-out (cup) competitions. Then we explain the revenue variables that we have employed. So, in Section 4 we use a visual approach ${ }_{2}$ as do Deloitte and Touche $(2000 \mathrm{~b})$. This allows us to test the sort of function most appropriate to revenues. We analyse the relationship between performance on the pitch and the different incomes of the club. The section ends with an analysis of the correlation between revenues and expenses in order to understand the ability of clubs to obtain profits. The following step, in section 5 , consists of testing the influence of sports performance on economic results. We do this by means of a descriptive statistical study and a regression analysis. Finally, we present our conclusions.

\section{The SAMPLe}

The fact that the aim of this study links financial and sports performance variables leads us to deal with data from financial statements. Ideally, we would have liked to work with data from all Spanish professional football clubs, but it is impossible to find the financial information for every club. Despite the fact that Spanish companies must submit their annual financial report to a public register, a high number of Spanish Sociedades Anónimas Deportivas (SADs) ${ }^{3}$ do not fulfil this requirement, at least on time. In the case of those clubs that are not companies, since they do not have this obligation, it is only possible to access their accounts if they supply them personally.

\footnotetext{
${ }^{3}$ In Spain, football clubs had to become (sporting) companies in early 1990s, although those which fulfilled certain economic requirements, such as having a positive net worth at that time, could remain as clubs. The sports companies in Spain are called Sociedades Anónimas Deportivas (S.A.D.).
} 
We requested the annual accounts of all clubs in the Spanish First and Second Division for the period under study (1998-2002). When the individual SAD did not provide us with the information requested, we sought it in the corresponding public register. We obtained those annual accounts that had been submitted to the register by September 2003.

This is the reason why we eventually worked with a wide sample of clubs rather than the total number. We have analysed a sample of 134 valid cases for the statistic and econometric work. These cases correspond to 34 different clubs from the Spanish First and Second Division "A" during the period 1998-2002. Considering that each year a club's features (the division in which it plays and its results) change, the sample consists of 84 First Division clubs and 50 from the Second Division "A". So, each club is a different case for each year. We understand that, for the purpose of this study, that the sporting and financial behaviour of the club might change from season to season or, on the contrary, if a club has a clear policy that relates its economic results with the team performance then it would be consistent through time and the econometric analysis would detect this.

\section{THE MEASUREMENT OF SPORTS PERFORMANCE}

The measurement of sports performance depends on the competition under scrutiny and the perspective on which the study is focused. For example, if the object of analysis is the effect of performance on the pitch on attendance, it will be more useful to employ variables such as the 'percentage of victories' (Dawson et al., 2000; Marques, 2002; Boulier and Stekler, ${ }^{4}$ 2003), 'number of goals scored by match' (Palacios-Huerta, 2002), 'team's goal average weighted by relative quality of rival team' (Koning et al. 2001), 'score/goal difference' (Boulier and Stekler, 2003; Palacios-Huerta, 2002), and even variables which incorporate the 'playing style' (Cocco and Jones, 1997). Koning (2003) working on an evaluation of the effect of hiring coaches on team performance used 'average goal difference,' 'goals conceded,' and 'goals scored.'

Studying forecast models, Goddard (2005) develops two approaches: goalsbased and results-based models. The variables he employs are 'goals scored', 'goals conceded' and 'results' (with a 'points score' of 1 point for a win, 0.5 for a draw and 0 for a defeat).

If the study focuses on open league competitions, the variables will be of 'ranking' or 'points obtained' type. We are able to measure these variables in several ways. Some of them may be direct such as 'points obtained in league' (Gerrard, 2001). Others will be formulated adjusting it with some kind of reference, for example, 'points obtained in league over all possible points' (Dawson et al., 2000). For these types of measurements, we have decided to employ the 'points obtained in league' variable, as Gerrard does, but accumulating the points obtained for the champion of the Second Division to those obtained by

\footnotetext{
${ }^{4}$ In this case it is applied to the NFL.
} 
each team in the First Division. This variable will be called accumulated points (ACPTS).

When the tendencies over several seasons are analysed, average values are employed. They may be 'position average value' (Deloitte \& Touche, 2000 a) or 'average of modified variables' (Szymanski and Kuypers, 1999).

'Final league ranking' may be used directly as a variable (Magaz, 2002). However, this measure is not very useful for our purposes as it presents an inverse relationship with most of the variables we are going to employ. The sign of the coefficient of the regression line will be negative due to an ordinary ranking assigning the least value to the team with the best performance. This is the reason why most of authors work with modified variables that we call 'ranking measures', $\mu\left(C_{1}\right)$, where $\mu$ is a monotone decreasing function of ranking. Dobson and Goddard (2001) suggest:

$$
\text { (1) } \mu\left(\mathrm{C}_{1}\right)=\frac{\mathrm{n}+1-\mathrm{p}}{\mathrm{n}}
$$

Where $n$ is the number of teams who take part in the competition and $p$ is the position they achieved in the ranking.

In this line, the formulation employed by Szymanski and Kuypers (1999) is:

$$
\text { (2) } \mu\left(\mathrm{Cl}_{1}\right)=-\log \left(\frac{\mathrm{p}}{\mathrm{n}+1-\mathrm{p}}\right)
$$

As they work with 92 teams, the expression above becomes:

$$
\text { (3) } \mu\left(\mathrm{C}_{1}\right)=-\log \left(\frac{\mathrm{p}}{93-\mathrm{p}}\right)
$$

We are going to estimate the league ranking, as a measure of sports performance, following along the lines of Szymanski and Kuypers (1999) working with the following expression:

$$
\text { (4) } \mu\left(C_{l}\right)=-\log \left(\frac{p}{43-p}\right)
$$

The difference with Szymanski and Kuypers' formula lies in the number of clubs involved. Due to the fact that professional football in Spain consists of 20 clubs in the First Division and 22 Second Division "A" clubs, the total number of clubs involved in our study is 42 . For this reason we take $43(n+1)$ in the denominator. Finally, as far as 'position' is concerned, we take the end of the season ranking. First Division rankings range from 1 (the top club) to 20 (the bottom club). The top of the Second Division will rank as $21^{\text {st }}$ position; the second one will be 
place as $22^{\text {nd, }}$ and so on, until the bottom of the Second Division, who will be graded $42^{\text {nd }}$. We call this league position variable LPOS.

When we deal with other types of competitions, with a knock-out (cup) format, the measurement of the variable becomes complex. In fact, no author has previously suggested a measurement. Almost all the research papers work exclusively with league results since that type of competition is more easily measurable and, being a stable and regular competition, it reflects the ability to achieve financial and sporting results in the long term. Besides, league position implies future expectations about participation in European competitions, promotion or relegation.

Baimbridge (1997) carries out a study about the effects of a knock-out competition: the 1996 European Championship. Nevertheless, due to his focus on attendance he does not develop a variable for measuring sports results. Koning et al. (2001) research a cup competition too in order to forecast results. However, they do not provide measures for the variables we are going to study. For this reason we have had to design a system for measuring performances in the Copa del Rey ${ }^{5}$, the UEFA Champions' League and the UEFA Cup.

Due to the fact that the cup competition system works neither on a ranking basis nor employs points, we have developed a method for expressing the position of a particular team within cup competitions. We shall apply this ranking to the participation of clubs in the Copa del Rey, the UEFA Champions' League, and the UEFA Cup. We shall only take into account the Intertoto Cup if the club qualifies for the UEFA Cup because it is a less important competition played in the summer, often with reserve team players.

Figure 1. Diagram of measurement of result variable for cup-style competitions

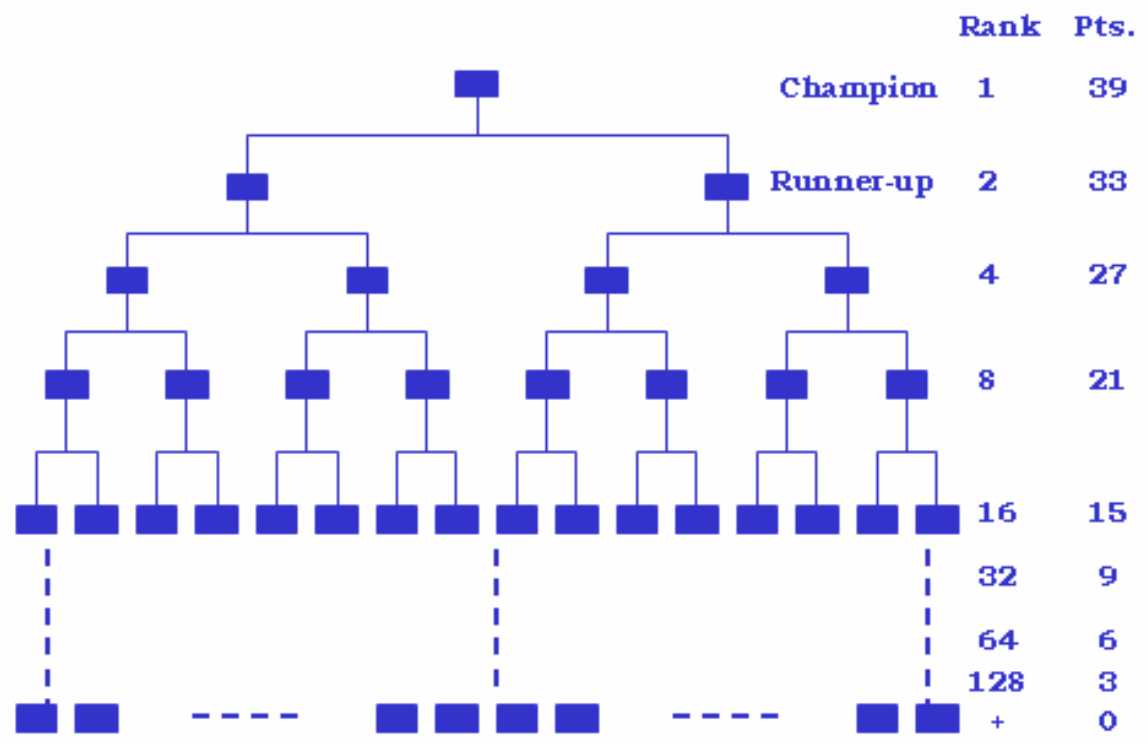

\footnotetext{
${ }^{5}$ The Spanish Cup organised by the Real Federación Española de Fútbol (the Spanish Football Association)
} 
Figure 1 shows the assignation of position and point schema for cup-style competitions. This model has been applied to the Copa del Rey and UEFA Cup competitions. We develop a ranking and assume that the champion would be placed first and the runner-up second. Below these two places, which are decided in the final game of the competition, the teams who did not qualify in each round are at the same level. The two losing semi-finalists do not play each other in order to determine who comes third or fourth. Therefore, we have opted for ranking both failed semi-finalists as $4^{\text {th }}$. In previous rounds the same principle applies, and teams who have been knocked out of the competition in the same round will be awarded the same ranking. Hence we have ranked as $8^{\text {th }}$ all the teams who lost in the quarter-finals. Accordingly, the 8 teams eliminated in the previous round are ranked $16^{\text {th }}$, the 16 teams knocked-out in the round prior to that are graded $32^{\text {nd }}$, and so on.

The points are allocated taking into account the fact that the first rounds are played in one leg in the Copa del Rey. In this case, the team that qualifies necessarily has had to win that match. Applying the league points system, we award 3 points to the winning teams in that round. This above framework does not work in European competition. ${ }^{6}$ However, we think that there is an argument to keep the points awarded the same in our system as the competitions have a limited number of matches. For this reason, we decided to keep the weighting of 3 points for a win in order to mark the effects of progressing to the next round. From the round of 16 teams onwards, we award 6 points to the teams that go through to the following round. This would have applied anyway when a team had won both matches, but this might not necessarily happen. A particular team might qualify after drawing both legs (because of the 'away goal counts double' rule in cases of drawn aggregates), or after winning one and drawing the other match. In these cases, following the league point system, the team would have achieved 2 or 4 points respectively. However, as is illustrated in Figure 1, we have opted for allocating 6 points to the winning team in each round - even in the final - because we think that what matters is to establish the difference between the teams that progress in the competition and those that fare knocked out.

In estimating the points for UEFA Champions' League, we award no points to those teams that do not take part in the competition. Due to the lesser importance of the first stages of the competition - and in order to not penalise clubs who have qualified directly - we assign 1 point for each match won and 0.5 for drawn matches during the qualifying rounds. The points for the matches played during the group stage are in accordance with the UEFA criteria; that is, 3 points for a victory and 1 for a draw. In order to weight the qualification to the next phase, ${ }^{7}$ we give 5 additional points for qualification for that stage. We award 1 additional point, added to the previous 5 (to make 6 ) for qualifying to

\footnotetext{
${ }^{6}$ Since the 2004/05 season, the structure of the UEFA Cup competition has changed including a mini-league group stage. Therefore, the system of allotting points might be similar to the UEFA Champions' League.

${ }^{7}$ During the years of this study there were two group stages. Nowadays there is only one group stage and then the final knock-out phase. This implies that in order to apply this system some adjustment would be necessary to accommodate the changing competition structure.
} 
the second group stage, 7 for reaching the quarter-finals, 8 for the semi-finals and 9 for winning the final. Furthermore, we also allot 3 points for winning and 1 for drawing during the final phase which is played as a knock-out competition. Those teams that are eliminated from the UEFA Champions' League and join the UEFA Cup will get points from both competitions.

In the League, we accumulate the points achieved by the First Division teams onto the number obtained by the Second Division Champions each year. We also use the points from other competitions according to the schema explained above.

In order to measure the effect of all the important competitions combined, we have defined a compound index (IND) which consists of the points achieved in each competition. These are weighted according to the importance of the competition for the overall valuation of the performance of the team.

If $P i$ represents the points achieved in the $i$ competition and $\alpha i$ represents the weight of each competition considered (the Copa del Rey, UEFA Cup, League, UEFA Champions' League) then the compound index (IND) may be expressed as:

$$
\mathrm{IND}=\sum_{\mathrm{i}=1}^{4} \alpha_{\mathrm{i}} \mathrm{Pi}
$$

We have chosen the weightings to develop the compound index by taking into account the relative importance that they have for the clubs from an economic viewpoint. So, the Copa del Rey is weighted as 1; UEFA Cup (and Cup Winner's Cup, when it existed) and the League are weighted as 2; and UEFA Champions' League (UCL) as 3. We do not think that it is necessary to weight the League competition higher because every team plays a large number of matches and, consequently, the accumulated points will already have a bonus value, especially for First Division teams who accumulate the points of the Second Division Champions. The expression of this index will be thus:

(5) IND = Cup Pts. + 2•UEFA Pts. + 2•League Pts. + 3•UCL Pts.

\section{INFLUENCE OF SPORTS PERFORMANCE ON REVENUES}

As we said at the beginning of the paper, there exists general agreement that good performance on the pitch will bring higher incomes (Szymanski and Kuypers, 1999; Deloitte \& Touche 1999, 2000 b). These are not the only authors who consider the club's revenues as a function of sports performance exclusively or considered alongside other factors. For example, El Hodiri and Quirk (1971) express the incomes of a sporting club as a function of the population in which it is based and the sports performance is measured by a win ratio. Haan et al. (2002) explain the total turnover according to a club's ticket sales a consequence of income derived from the quantity of squad talent - and the money for winning linked to the likelihood of victory the club has. Finally, Hoehn and Szymanski (1999), within the context of an analysis of competitive balance, 
determine a club's revenues, along with other factors, from the percentage of victories each team gets.

Taking this theoretical background as reference, we are going to test if a better sports performance is a source of higher revenues for Spanish clubs. We seek the verification of this hypothesis by mean of a simple univariate regression analysis. Previously, we have observed that the relationship between income and performance on the pitch has an exponential character. As a consequence of this, the highest-ranked teams usually have much higher turnover than the lowest-ranked ones. Besides, the difference in incomes among the lowest-ranked teams is much less significant. Hence, we decided to work with the logarithm of income variables.

Figure 2. Budget, number of members and league ranking (Season 2001/2002)

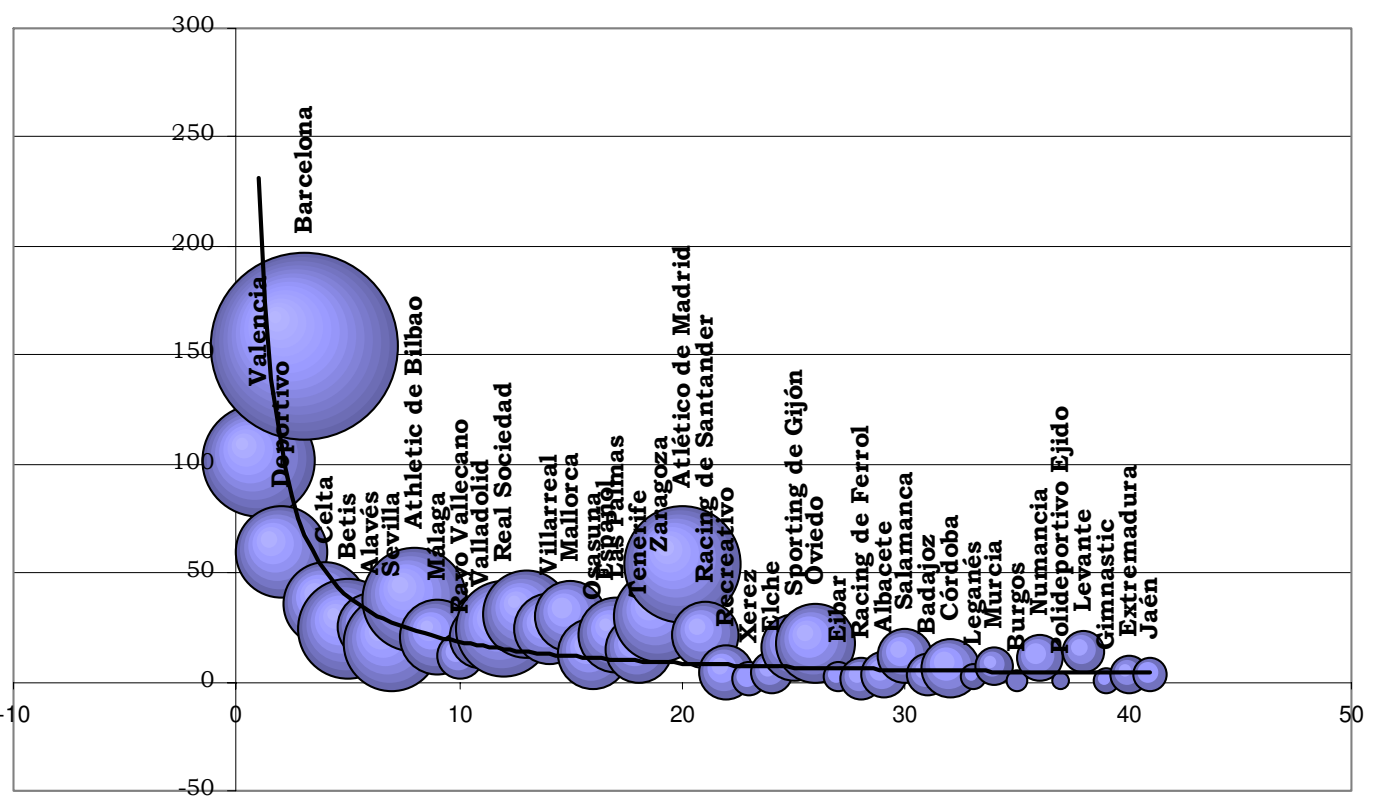

In order to corroborate what we have just asserted above, we have followed the visual model employed by Deloitte and Touche (2000) and we have performed a similar analysis with all the Spanish clubs ${ }^{8}$ during the 2001/2002 season. The results are shown in Figure 2 . In this case, the budget ${ }^{9}$ (in millions of euros) is represented on the y-axis, while the ranking in the League for that season appears on the x-axis. The width of the bubble represents each club's number of members. Figure 2 also includes the line that adjusts the exponential regression between budget and ranking in league. The level of explanation of that regression is $55.12 \%$. It would be better if teams as Atlético de Madrid, Racing de

\footnotetext{
${ }^{8}$ We have had to exclude Real Madrid from the sample since its budget for that season was extraordinarily inflated as consequence of the sale of the land of its training grounds sited in the city.

${ }^{9}$ Budget is defined from expected total income. In this sense our approach is similar that of Deloitte and Touche.
} 
Santander and Oviedo (with budget more suitable to First Division) were in the top flight of Spanish football in that season.

It is worth explaining the income variables with which are going to work. We must remember that these variables are conditioned by the information that clubs report in their annual accounts.

We are going to work with the variables 'sporting revenues' (SR) and 'season tickets' (ST), which incorporates revenues from season tickets, membership and executive boxes. The sporting revenues variable (SR) represents $77.2 \%$ of the net ordinary income of Spanish football clubs and the season ticket revenues (ST) represent the remaining $22.8 \%$.

The variable 'sporting revenues' (SR) gathers information from other incomes. It consists of information from different constituents, namely, the income from match tickets and the pools (combined as the TAP variable), television rights (TV) and advertising/sponsorship (ADV). The sporting revenues variable can, then, be called a 'summarising variable'. However, it is not unusual for this 'summarising variable' to have a higher value than the sum of its constituent variables. The reason for this might be that some clubs provide an abbreviated form of their accounts and only report the summarising variables. So, not all clubs provide full information about each constituent of every variable. This will affect the number of valid cases for each variable.

The Spanish rules of accountancy state that clubs have to register as 'Sporting Revenues' the incomes from their main activity, which is the participation in sporting competitions. These rules stipulate that the SR account include incomes such as commercials, broadcasting rights, advertising, sponsorship and pools share.

The variable 'Tickets and Pools' (TAP) represents the incomes from sporting competitions and from the pools. Apart from the income from ticket sales, in some cases, clubs might register in this account prizes for taking part in competitions, and similar funds. The revenues from sporting competitions represent $15.7 \%$ of sports revenues of the sample. The 'pools' account is the appropriate one for registering the share that a particular club receives in pools money. It would be interesting to consider both tickets and pools accounts separately, but the level of valid cases for the 'pools' variable is low (44.1\%). The reason is that many clubs combine the information for tickets and pools within a single account. Hence, we have decided to work with a variable that is the sum of both accounts (TAP). This variable represents $16.3 \%$ of sporting revenues.

The variable 'TV rights' (TV) subsumes, in general, all the revenues linked to the cession of broadcasting, internet and other rights. This variable has to be considered for its relevance within the conceptual schema of the football business as well as for its importance as a revenue stream (TV revenues constitute $46.7 \%$ of sporting revenues). Sevilla CF, for two seasons, combined its information on incomes from television rights and advertising. In our sample, we have included both elements within the TV variable. 
The last variable that forms part of sporting revenues is 'advertising' (ADV). This variable represents $20 \%$ of the total amount of sporting revenues. Although the name of the variable is advertising, it includes sponsorship as well.

Incomes from the main activity, but related to membership fees, membership cards, season tickets, and so on, are accounted as 'season tickets' (ST). As was mentioned earlier, this variable shows an important weighting in the net ordinary income $(22.8 \%)$.

Now that the variables have been explained, we can present the results achieved from the regression analysis. We have had to exclude Real Betis from the sample due to the fact that it has handed over all its exploitation rights to a service company and hence it does not enter any amount in the income accounts that are analysed here.

Due to the exponential character of the functions of revenues explained above, we have worked with their logarithm. For this reason, we have expressed the variables with the prefix 'L'.

Table 1. Statistics of regression between sports performance and revenues.

\begin{tabular}{|c|c|c|c|c|c|c|c|}
\hline$\underline{L S R}$ & $R^{2}$ & $t$ & sig. & $\underline{L A D V}$ & $R^{2}$ & $t$ & sig. \\
\hline LPOS & 0,722 & 18,143 & 0,000 & LPOS & 0,587 & 11,735 & 0,000 \\
\hline ACPTS & 0,775 & 20,940 & 0,000 & ACPTS & 0,513 & 10,105 & 0,000 \\
\hline IND & 0,885 & 29,371 & 0,000 & IND & 0,669 & 13,644 & 0,000 \\
\hline LTAP & $R^{2}$ & $t$ & sig. & $L S T$ & $R^{2}$ & $t$ & sig. \\
\hline LPOS & 0,592 & 12,102 & 0,000 & LPOS & 0,599 & 12,872 & 0,000 \\
\hline ACPTS & 0,496 & 9,968 & 0,000 & ACPTS & 0,538 & 11,363 & 0,000 \\
\hline IND & 0,739 & 16,413 & 0,000 & IND & 0,668 & 14,128 & 0,000 \\
\hline$L T V$ & $R^{2}$ & $t$ & sig. & & & & \\
\hline LPOS & 0,612 & 12,497 & 0,000 & & & & \\
\hline ACPTS & 0,731 & 16,412 & 0,000 & & & & \\
\hline IND & 0,745 & 16,400 & 0,000 & & & & \\
\hline
\end{tabular}

Note: dependent variables are shown in bold italics

Table 1 shows the results that we have reached. Based on this information we can state that, in general, the different measures for the sports performance variable explain to a high percentage and in a statistically significant way the main revenue streams of Spanish professional football clubs. It appears that sports performance does indeed affect the main revenues of a football club in Spain. These outcomes agree with those reached by Szymanski and Kuypers (1999), particularly referring to sporting revenues. Besides, the behaviour of the compound index (IND) is especially good for explaining revenues of clubs.

The variable that best explains the performance on the pitch (independent of the measure used) is the sporting revenues (SR), as might be expected. Also the revenues from television rights (TV) explain sports results strongly. 
Finally, as we pointed out in the introduction, the main aim of our work is to check whether or not sports performance influences economic results. Since the bottom line is a consequence of the subtraction of expenses from turnover, in addition to the study of the relationship between sports performance and revenues, an analysis of the sports performance on expenses (or a similar study) would be appropriate. We have opted to test the existence of a correlation between revenues and expenses. If a relationship exists, then the regression analysis would give an outcome of analogous results such as that which we obtained previously. A very high correlation exists between revenues and costs. It is significant at a 0.01 level (2-tailed) and the value of the correlation between sporting revenues and staffing costs for the sample under consideration is $93.2 \%$. This means that the main expenses account is going to have practically the same patterns of behaviour as the core account of ordinary income. Bearing in mind that staffing costs represent approximately $70 \%$ of total incomes of Spanish football clubs, it is logic to conclude that profits will not be high. In this case, it means that sports performance will have little explanation power over economic results. This issue is will be analysed further in the following section.

\section{INFLUENCE OF SPORTS PERFORMANCE ON ECONOMIC RESULTS}

Now, we will provide empirical evidence to support (or reject) the theories outlined at the start of this paper. Independent of what the core football business concept might be, of whether or not football clubs are profit-maximisers, each of the following proposals implies that there is no relationship between sports performance and economic results: 1) balance between sports performance and profit of the club in the long term (Szymanski and Kuypers, 1999); 2) seeking the best possible sports performance while maintaining financial solvency (Morrow, 1999); 3) looking to maximise sports performance once the minimum profit levels have been achieved (Gerrard and Dobson, 2000); 4) considering null profit as the aim: or 5) that once the economic target has been satisfied, any the excess resources will be spent on improving the squad (Guijarro et al., 2000).

The hypothesis that is tested here is the following: even when clubs achieve good sporting performances, this does not condition their economic results, or if it does, it does so only weakly.

Prior to the econometric analysis, a statistical study was carried out of profit before and after taxes, total turnover of ordinary activities and extraordinary results. With this analysis we try to find out if, on average, the economic results of Spanish football clubs tend to be close to zero; also if the average profit represents an high percentage of revenues; and, finally, to show the relevance of extraordinary results in the Spanish clubs' profit an loss account. 
Table 2. Statistics on revenues and economic results (1st \& 2nd Divisions, 1998-2002)

\begin{tabular}{lrrrr}
\hline \multicolumn{1}{c}{ (data in euros) } & \multicolumn{1}{c}{ Mean } & \multicolumn{1}{c}{ Median } & \multicolumn{1}{c}{ Std. Deviat. } & \multicolumn{1}{c}{ Range } \\
\hline Net Profit & 375,963 & 116,632 & $7,090,508$ & $74,326,842$ \\
Profit before taxes & 713,386 & 144,937 & $7,862,456$ & $74,326,842$ \\
Total Ordinary Revenue & $24,355,909$ & $14,853,016$ & $31,503,993$ & $162,241,342$ \\
Extraordinary Results & $12,441,800$ & $5,674,272$ & $32,636,209$ & $340,094,785$ \\
\hline
\end{tabular}

Table 3. Statistics on revenues and economic results (1st Division, 1998-2002)

\begin{tabular}{lrrrr}
\hline \multicolumn{1}{c}{ (data in euros) } & \multicolumn{1}{c}{ Mean } & \multicolumn{1}{c}{ Median } & \multicolumn{1}{c}{ Std, Deviat, } & \multicolumn{1}{c}{ Range } \\
\hline Net Profit & $1,900,872$ & 271,123 & $7,795,448$ & $68,874,178$ \\
Profit before taxes & $2,427,858$ & 434,216 & $8,759,167$ & $68,874,178$ \\
Total Ordinary Revenue & $35,447,344$ & $21,514,165$ & $35,285,960$ & $155,501,863$ \\
Extraordinary Results & $18,097,299$ & $9,206,201$ & $40,134,718$ & $340,094,785$ \\
\hline
\end{tabular}

Table 4. Statistics on revenues and economic results (2nd Division, 1998-2002)

\begin{tabular}{llrrl}
\hline \multicolumn{1}{c}{ (data in euros) } & Mean & \multicolumn{1}{c}{ Median } & \multicolumn{1}{c}{ Std, Deviat, } & Range \\
\hline Net Profit & $-2,185,883$ & $-628,130$ & $4,779,430$ & $29,296,696$ \\
Profit before taxes & $-2,166,927$ & $-571,190$ & $4,932,384$ & $29,460,736$ \\
Total Ordinary Revenue & $5,722,298$ & $4,229,989$ & $4,438,351$ & $22,102,473$ \\
Extraordinary Results & $2,940,562$ & $1,363,823$ & $3,950,782$ & $19,006,563$ \\
\hline
\end{tabular}

We find that the average net profit of Spanish football clubs during the period of study is slightly positive but with a more robust estimator, as the median is, this result decreases remarkably. There is a wide range among the economic results obtained for clubs over the period of study and a high standard deviation. This would mean that extreme values would influence the average.

Another point worth highlighting is the small proportion that expected profit represents with respect to the total ordinary revenue and the extraordinary results. This implies a high volume of expenses.

The results, dividing the sample according the division in which the club belonged in each season, illustrate that in First Division on average the clubs make a profit, while in Second Division they lose money. In addition, in this case, it is notable that the amount of average losses is more than a third (in absolute terms) of the total ordinary revenue.

Nevertheless these data are not enough when we try to test that, in general terms, the profit of Spanish football clubs tends to be null. For this reason a frequency analysis was carried out in order to find out the distribution function of the economic results of the sample. Figure 3 shows us a clear concentration of profits and losses around zero. The fact is that $91.8 \%$ of the clubs in the sample make a profit of less than 10 million euros and greater than -10 million euros. Besides, $31.1 \%$ of the clubs have profit of less than 500,000 euros. 
Figure 3. Net Profit distribution function

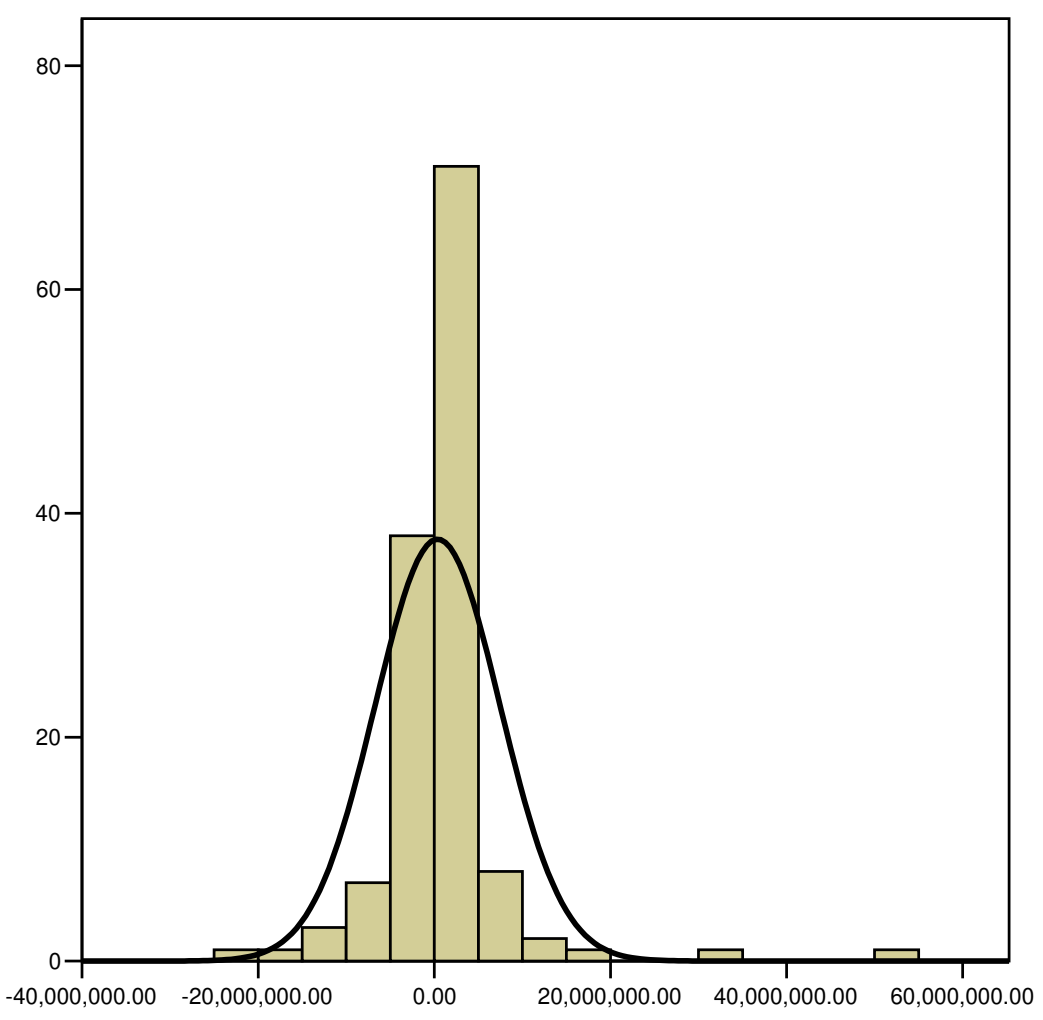

In a second stage, we have carried out a univariate ordinary least squared (OLS) regression analysis in order to verify the hypothesis proposed at the start of this section. The dependent variable we have employed is the Net Profit of football clubs and SADs. The independent variable is performance on the pitch. We have used the measurement of sports performance outlined earlier, that is, a measure of ranking (LPOS, according to expression (4)), of accumulated points obtained (ACPTS), and the compound index (IND estimated as indicated in (5)).

Table 5. Statistics of regression between sports performance and economic results.

\begin{tabular}{lccc}
\hline Independent variables & $\mathbf{R}^{\mathbf{2}}$ & $\mathbf{t}$ & $\mathbf{S i g}$ \\
\hline LPOS & 0,080 & 3,387 &, 001 \\
ACPTS & 0,090 & 3,621 &, 000 \\
IND & 0,141 & 4,255 &, 000 \\
\multicolumn{2}{l}{ Dependent variable: NP (Net Profit) } \\
\hline
\end{tabular}

The outcome of the regression shows us that the independent variables explaining power is considerably low. The compound index (IND) explains only $14 \%$ of the net profit of Spanish football clubs. The other two variables demonstrate an even poorer explanation power, as they do not even explain $10 \%$ of the dependent variable. Consequently, other causes not included in the model have a higher explaining power than sports performance. So, we may suppose that the sports performance has little conditioning effect on economic results of football clubs and SADs. 
We have also checked the relationship analysed in Table 5 considering only data from season 1999-2000. The idea was to test if a higher explanation power would be found in a shorter term. However, the results obtained are even worse ( $R^{2}$ of $0.018 ; 0.001$ and 0.089 for LPOS, ACPTS and IND respectively).

We may find an explanation for this outcome in Table 2. As has already been pointed out, it can be observed that the mean of clubs' net profit is very low, especially if we compare it with the mean of revenues. The average net profit only represents $1.5 \%$ of the mean of the total ordinary revenues. Taking a most robust estimator as median, the percentage falls to $0.8 \%$. These facts support the hypothesis that the Spanish clubs tend to null profit. However, at the same time, we have to be prudent when we interpret these figures because of the high dispersion in the data that we have found.

\section{Conclusions}

We have found that there is a non-linear relationship, with an explanation degree of $55.12 \%$, between budget (expected income) of Spanish football clubs and sports performance. This outcome is consistent with the findings of Deloitte and Touche (2000).

Independent of the measurement to reflect sports performance, it explains in a high and statistically significant way the main sources of revenues of Spanish football clubs. Due to the characteristics of the sample and the way that the clubs report their financial statements, the 'sporting revenues' is the best variable to explain performance on the pitch. These results concur with those obtained by Szymanski and Kuypers (1999) for English football.

The compound index (IND), which reflects the performance of the team in the main competitions, shows the highest degree of explanation of the different revenues streams of Spanish football clubs. We think that the most relevant point here is the fact that we did not limit our data to results of league competitions. We are aware that the system designed by us is open to discussion, but what is clear is that it is worth working with measures of performance that include all the competitions in which the club is involved.

We have proven the existence of a very high, significant correlation between 'sporting revenues' and the main expenses account, that is, staffing costs. Taking into account that staffing costs represent more than $70 \%$ of total incomes in Spanish football clubs, it is not surprising that we found that the average net profit of Spanish football clubs in the period 1998-2002 to be only slightly positive. If we split the sample between First and Second Divisions, the result is that the average First Division clubs shows a profit while the average Second Division club shows a loss. Even in the case of First Division clubs, the average net profit obtained represents an undersized proportion of total ordinary revenue. Furthermore, after a study of frequencies, we found an important concentration of cases in the sample with a net profit around zero.

Finally, the results of the regression analysis between sports performances and economic results during the period 1998-2002 show us that sports performance 
has almost no explanation power of economic results. Following the approach of Szmanski and Kuypers (1999), and trying to verify whether or not in the short term a higher relationship could exist, we have tested the dependence between both variables in the 1999-2000 season, and the results are even worse. So we have to conclude that in Spanish football there must be other causes notincluded in the model (economic results $=f$ [sports performance]) with a higher power to explain economic results than performance on the pitch.

\section{References}

Baimbridge, M. (1997). Match attendance at Euro 96: was the crowd waving or drowning?. Applied Economics Letters, 4, pp. 555-558.

Boulier, B. L., \& Stekler, H.O. (2003). Predicting the outcomes of National Football League games. International Journal of Forecasting, 19, pp. 257-270.

Cocco, A., \& Jones, J.C.H. (1997). On Going South: the Economics of Survival and Relocation of Small Market NHL Franchises in Canada, Applied Economics, 29, pp. 1537-1552.

Dawson, P., Dobson, S., \& Gerrard, B. (2000). Estimating Coaching Efficiency in Professional Team Sports: Evidence from English Association Football. Scottish Journal of Political Economy, Vol. 47, No. 4, September, pp. 399-421.

Deloitte \& Touche (1999). Informe Anual 1996/97 sobre las Finanzas en la Primera División del Fútbol en España. Deloitte \& Touche.

Deloitte \& Touche (2000 a). Annual Review of Football Finance, A review of the 1998/1999 season. Deloitte \& Touche, august.

Deloitte \& Touche (2000 b). Informe Anual 1997/98 y 1998/99. Las Finanzas en la Primera División del Fútbol en España. Deloitte \& Touche.

Dobson, S., \& Goddard, J. (2001). Revenue Divergence and Competitive Balance in a Professional Sports League. Working Paper en http://econserv2.bess.tcd.ie/DEW/qub1dobson.doc.

El Hodiri, M., \& Quirk, J. (1971). An economic model of a profesional sports league, Journal of Political Economy, Vol. 79, pp. 1302-19.

Gerrard, B. (2001). A New Approach to Measuring Player and Team Quality in Professional Team Sports. European Sport Management Quarterly. Vol. 1 - n. 3. September, pp. 219-234.

Gerrard, B. (2002). Going down, going down, going down: the economics of relegation. Comunicación al 10th EASM Congress. Jyväskylä, 4-7 Septiembre.

Gerrard, B., \& Dobson, S. (2000). Testing For Monopoly Rents in the Market for Playing Talent. Journal of Economic Studies. Vol. 27 - n. 3, pp. 142-164.

Goddard, J. (2005). Regression models for forecasting goals and match results in association football. International Journal of Forecasting, 21(2), 331340. Retrieved July 27, 2005, from EconLit database. 
Guijaro, F., Blasco, A., Rival, F. J., \& Rodríguez, J. A. (2000). Aplicación de Costes Presupuestarios para la Valoración de Marcas de Clubes de Fútbol Españoles. Comunicación al Congreso ACODI, Octubre.

Haan, M., Koning, R. H., \& Witteloostuijn, A. van (2002). Market Forces in European Soccer. Communication to $17^{\text {th }}$ Annual Congress EUROPEAN ECONOMIC ASSOCIATION, $25^{\text {th }}$ January .

Hoehn, T., \& Szymanski, S. (1999). The Americanisation of European Football. Economic Policy, April, pp. 205-240.

Koning, R. H. (2003). An econometric evaluation of the effect of firing a coach on team performance. Applied Economics, 35, 555-564

Koning, R. H., Ridder, G., Koolhaas, M., \& Renes, G. (2001). Simulation Model for Soccer Championships, University of Groningen, SOM Research Reports $01 \mathrm{~A} 66$.

Magaz, A. M. (2002). Los Resultados del Sector de Fútbol Profesional. Comunicación al Congreso Científico Internacional de Fútbol Salamanca 2002. Mayo.

Marques, A. (2002). Competitive balance in the Portuguese premiere league of professional soccer. Working Papers in Economics. RePEc:wpa:wuwpio:0211025.

Morrow, S. (1999). The new bussines of Football: Accountability and Finance in Football. Palgrave Macmillan, Houndmills.

Murphy, P. (1999 a). Banking on Success: Examining the Links Between Performance and the Increasing Concentration of Wealth in English Elite Football, Singer \& Friedlander. Review 1998-99 Season, pp. 37-44.

Murphy, P. (1999 b). For Richer, for Poorer North of the Border: Examining the Link Between Resources and Performance in Scottish Elite Football, Singer \& Friedlander. Review 1998-99 Season, pp. 45-49.

Noll, R. G. (2002). The Economics of Promotion and Relegation in Sports Leagues: The Cases of English Football. Journal of Sport Economics; 3(2), May, pp. 169-203.

Palacios-Huerta, I. (2002). Structural Breaks During a Century of the World's Most Popular Sport, Working Paper, Brown University, March.

Sloane, P. (1971). The economics of professional football: the football club as a utility maximiser. Scottish Journal of Political Economy, 17, pp.121-146.

Szymanski, S. \& Kuypers, T. (1999). Winners and Losers: The Business Strategy of Football. Penguin, Harmondsworth. 